\title{
Penurunan Kadar Surfaktan Anionik dan Fosfat dalam Air Limbah Laundry di Kawasan Keputih, Surabaya Menggunakan Karbon Aktif
}

\author{
Wahyu P. Utomo, ${ }^{1 *}$; Zjahra V. Nugraheni ${ }^{1}$; Afifah Rosyidah, ${ }^{1}$, Ova M. Shafwah, ${ }^{1}$ Luthfi K. Naashihah, ${ }^{1}$ Nia \\ Nurfitria, ${ }^{2}$ Ika F. Ulfindrayani, ${ }^{3}$ \\ ${ }^{1}$ Departemen Kimia, Institut Teknologi Sepuluh Nopember (ITS). Kampus ITS Sukolilo, Surabaya \\ ${ }^{2}$ Jurusan Matematika, Universitas PGRI Ronggolawe, Tuban \\ ${ }^{3}$ Jurusan Teknik Kimia Fakultas Teknologi Industri, Institut Teknologi Pembangunan Surabaya \\ *Corresponding author: wp.utomo@chem.its.ac.id
}

\begin{abstract}
Abstrak
Limbah laundry merupakan salah satu limbah yang dapat mencemari lingkungan dan berdampak buruk bagi manusia. Penelitian ini bertujuan untuk menurunkan kadar surfaktan anionik (deterjen) dan fosfat yang terdapat dalam air limbah laundry di kawasan Keputih, Surabaya dengan menggunakan karbon aktif. Penurunan kadar surfaktan anionik dan fosfat menggunakan karbon waktif dengan variasi ukuran partikel yakni -60, -120 dan -200 mesh. Proses adsorpsi dilakukan dengan metode batch. Hasil yang diperoleh menunjukkan bahwa kadar surfaktan anionik pada limbah sebelum adsorpsi sebesar 10,65 ppm dan kadar fosfat sebesar 14,148 ppm. Kedua nilai tersebut berada diluar ambang batas yang ditetapkan pemerintah sebesar 100 ppm. Uji adsorpsi menunjukkan bahwa karbon aktif mampu menurunkan kadar surfaktan anionik dan fosfat secara signifikan. Kadar surfaktan anionik terendah setalah adsorpsi mencapai 3.102 ppm yang dihasilkan dari karbon aktif berukuran -200 mesh. Adsorpsi surfaktan anionik mengikuti model adsorpsi isotermal Freundlich. Sementara itu, kadar fosfat tidak terdeteksi setelah proses adsorpsi. Secara umum, semakin kecil ukuran karbon aktif, semakin besar kapasitas adsorpsinya terhadap surfaktan anionik dan fosfat.
\end{abstract}

Kata kunci: Karbon aktif; surfaktan anionik; fosfat; adsorpsi; deterjen

\begin{abstract}
Waste water from laundry industry is one of the waste water that can pollute the environment and harmful to humans. The aim of this research is to decrease the content of anionic surfactant (detergent) and phosphate contained in laundry waste water in Keputih area, Surabaya by using activated carbon. The decrease of anionic surfactnts and phosphate levels was carried out using activated carbon with particle size variations ie -60, -120 and -200 mesh. The adsorption process was done by batch method. The results showed that the anionic surfactant content of the waste water before adsorption was 10.65 ppm and the phosphate level was 14.148 ppm. Both values are beyond the government-set threshold of $100 \mathrm{ppm}$. The adsorption test showed that activated carbon was able to significantly decrease the content of the anionic and phosphate surfactants. The lowest anionic surfactant level after adsorption reaches 3,102 ppm produced from the 200-mesh activated carbon. Adsorption of anionic surfactants follows Freundlich's isothermal adsorption model. Meanwhile phosphate levels are not detected after the adsorption process. In
\end{abstract}


general, the smaller the size of activated carbon, the greater the adsorption capacity of anionic and phosphate surfactants.

Keyword: Activated carbon; anionic surfactant; phosphate; adsorption; detergent.

\section{Pendahuluan}

Air merupakan sumber daya alam yang krusial bagi kelangsungan hidup seluruh makhluk bumi. Kebutuhan air rata-rata umumnya adalah sebesar 60 liter/orang/hari untuk segala keperluannya. Pada tahun 2000, dengan jumlah penduduk dunia sebesar 6,121 milyar diperlukan air bersih sebanyak $367 \mathrm{~km}^{3}$, diperkirakan pada tahun 2025 diperlukan sebanyak $492 \mathrm{~km}^{3}$ dan pada tahun 2100 diperlukan $611 \mathrm{~km}^{3}$ air bersih per hari [1]. Salah satu sumber air yang banyak dimanfaatkan untuk memenuhi kebutuhan hidup manusia dan makhluk hidup lainnya yaitu sungai. Pada umumnya air sungai yang keluar dari mata air mempunyai kualitas yang baik. Namun dalam proses pengalirannya, air tersebut akan menerima berbagai macam bahan pencemar [2]. Beberapa tahun terakhir ini, kualitas air sungai di Indonesia sebagian besar dalam kondisi tercemar, terutama setelah melewati daerah pemukiman, industri dan pertanian [3]. Di negara-negara berkembang termasuk Indonesia, pencemaran domestik merupakan jumlah pencemar terbesar $(85 \%)$ yang masuk ke badan air. Sedang dinegara-negara maju, pencemar domestik merupakan $15 \%$ dari seluruh pencemar yang memasuki badan air.
Oleh karena itu, persentase kehadiran pencemar domestik di dalam badan air sering dijadikan indikator maju tidaknya suatu negara [4].

Salah satu limbah yang banyak menemari air sungai adalah limbah dari industri pencucian baju (laundry). Hal ini disebabkan karena limbah dari laundry mengandung deterjen yang mengandung beberapa potensi bahaya antara lain terbentuknya lapisan film dalam air akan menyebabkan menurunnya tingkat transfer ke dalam air, gangguan kesehatan yang cukup serius pada manusia, serta kombinasi antara polifosfat dengan surfaktan dalam deterjen dapat meningkatkan kandungan fosfat dalam air. Hal ini akan menyebabkan terjadinya entroikasi yang dapat menimbulkan warna pada air [5].

Deterjen anionik adalah kelompok yang paling banyak digunakan dimasyarakat khususnya untuk proses pencucian baju rumah tangga maupun industri laundry. Deterjen anionik ini mempunyai daya pembersih yang kuat, murah dan mudah diperoleh di masyarakat. Surfaktan anionik yang berasal dari sulfat adalah hasil reaksi antara alkohol rantai panjang dengan asam sulfat yang akan menghasilkan sulfat alkohol 
yang mempunyai sifat aktif permukaan (surface active agent: Surfactan). Jenis surfaktan anionik yang banyak digunakan sebagai deterjen antara lain alkil benzen sulfonat. Namun, saat ini alkil benzen sulfonat sudah banyak digantikan dengan alkil linear benzen sulfonat maupun natirum lauril sulfat yang dianggap lebih mudah terdegradasi [6].

Selain kandungan surfaktan anionik, keberadaan fosfat dalam limbah laundry juga cukup berbahaya bagi lingkungan. Fosfat terdapat dalam air alam atau air limbah sebagai senyawa ortofosfat, polifosfat dan fosfat organik. Setiap senyawa fosfat tersebut terdapat dalam bentuk terlarut, tersuspensi atau terikat di dalam sel organisme dalam air. Fosfat terlarut adalah salah satu bahan nutrisi yang menstimulasi pertumbuhan yang sangat luar biasa pada alga dan rumput-rumputan dalam danau, estuaria, dan sungai berair tenang. Batas konsentrasi fosfat terlarut yang diijinkan adalah $10 \mathrm{mg} / \mathrm{L}$ [7].

Terdapat beberapa metode yang dapat digunakan untuk menurunkan kadar surfaktan anionik dan fosfat dalam limbah laundry, antara lain filtrasi, proses fotokatalisis [5], koagulasi [8] dan adsorpsi [7]. Proses adsorpsi merupakan proses yang menarik untuk dikaji karena metode ini dapat dilakukan dengan berbagai jenis material, salah satunya adalah karbon aktif.
Karbon aktif dipilih karena memiliki daya serap yang tinggi yakni mencapai $25-100 \%$ terhadap senyawa organik ataupun anorganik serta luas permukaan yang besar berkisar antara 300-350 $\mathrm{m}^{2} / \mathrm{g}$ [7]. Oleh karena itu, dalam penelitian ini dilakukan penurunan kadar surfaktan anionik dan fosfat dalam limbah laundry yang diperoleh dari kawasan Keputih, Sukolilo, Surabaya menggunakan karbon aktif. Air sungai di kawasan Keputih ini dipilih karena merupakan kawasan pemukiman padat dengan banyak industry laundry skala rumah tangga. Ukuran partikel karbon aktif divariasikan untuk mengetahui pengaruhnya pada kapasitas adsorpsinya terhadap surfaktan anionik dan fosfat. Model adsorpsi surfaktan anionik juga dibahas dalam penelitian ini.

\section{Metode Penelitian}

\subsection{Alat dan Bahan}

Alat yang dibutuhkan dalam penelitian ini antara lain seperangkat peralatan gelas, neraca analitik, spektrofotometer UV-Vis (Genesis), kuvet, dan botol semprot.

Bahan yang diperlukan dalam penelitian ini adalah air limbah laundry yang diambil dari sungai di sektar Keputih, Sukolilo Surabaya, karbon aktif komersial (teknis), aquadest, $\mathrm{NaOH}, \quad \mathrm{H}_{2} \mathrm{SO}_{4}$, kloroform, indikator fenolftalin (PP), metilen biru, isopropil alkohol, $\mathrm{Na}_{2} \mathrm{SO}_{4}$, amonium molibdat, asam askorbat, kertas saring, kalium antimonil tartrat 
$\left(\mathrm{K}(\mathrm{SbO}) \mathrm{C}_{4} \mathrm{H}_{4} \mathrm{O}_{6} \cdot 1 / 2 \mathrm{H}_{2} \mathrm{O}\right), \quad$ dan $\quad$ kalium dihidrogen fosfat anhidrat $\left(\mathrm{KH}_{2} \mathrm{PO}_{4}\right)$, dan kertas $\mathrm{pH}$ universal.

\subsection{Penentuan kadar surfaktan anionik (deterjen) dengan metode MBAS (Methylene Blue Alkyl Sulfunate)}

Penentuan kadar surfaktan anionik (deterjen) dilakukan dengan metode MBAS sebagaimana yang telah dilakukan oleh Arneli (2010) [9]. Dalam penentuan kadar surfaktan anionik ini, larutan standar untuk pembuatan kurva kalibrasi maupun larutan sampel diperlakukan sama. Standar/Sampel air limbah sebanyak $50 \mathrm{~mL}$ dimasukkan ke dalam corong pisah yang telah disiapkan. Standar/sampel ditetesi dengan larutan $\mathrm{NaOH} \quad 1 \quad \mathrm{~N}$ agar standar/sampel berada dalam suasana basa yang diuji dengan indikator fenolftalein. Warna merah muda yang terbentuk dihilangkan dengan diteteskan larutan $\mathrm{H}_{2} \mathrm{SO}_{4} 1 \mathrm{~N}$ secara hati-hati hingga warna merah muda tepat hilang. Selanjutnya sebanyak $10 \mathrm{~mL} \mathrm{CHCl}_{3}$ dan 25 $\mathrm{mL}$ reagen metilen biru ditambahkan ke dalam corong pisah kemudian campuran dikocok selama 30 detik. Campuran selanjutnya ditambah dengan beberapa 10 $\mathrm{mL}$ isopropil alkohol untuk mengurangi terjadinya emulsi. Campuran didiamkan sampai terbentuk 2 lapisan. Lapisan $\mathrm{CHCl}_{3}$ dipisahkan dan dimasukkan ke dalam corong pisah lainnya. Ekstraksi $\mathrm{CHCl}_{3}$ diulangi sebanyak dua kali dengan menambahkan 10 $\mathrm{mL} \mathrm{CHCl}_{3}$ pada tiap ekstraksi.
Ekstrak $\mathrm{CHCl}_{3}$ yang terkumpul pada corong pisah kedua kemudian ditambahkan dengan $\quad 50 \mathrm{~mL}$ larutan isopropil alkohol $/\left(\mathrm{CH}_{3}\right)_{2} \mathrm{CHOH}$ dan dikocok selama 30 detik. Proses ekstraksi dilakukan pengulangan sebanyak dua kali dengan masing-masing ditambah $10 \mathrm{~mL} \mathrm{CHCl}_{3}$. Lapisan $\mathrm{CHCl}_{3}$ dipisahkan dan dimasukkan ke dalam labu ukur $50 \mathrm{~mL}$, kemudian dilakukan pengenceran hingga tanda batas. Selanjutnya dilakukan pembacaan serapan dari lapisan $\mathrm{CHCl}_{3}$ yang telah diencerkan dengan spektrofotometer UV-Vis pada panjang gelombang $653 \mathrm{~nm}$ dan hal yang sama juga dilakukan pada blanko. Penentuan kadar surfaktan anionik dengan metode MBAS ini dilakukan pada sampel limbah laundry sebelum dan sesudah proses pengolahan dengan karbon aktif.

\subsection{Penentuan kadar fosfat dan deterjen}

Penentuan kadar fosfat dilakukan dengan metode yang telah dilaporkan oleh Ndani (2016) [10]. Sampel air limbah laundry diambil sebanyak $50 \mathrm{~mL}$ dan dimasukkan ke dalam erlenmeyer. Sampel kemudian ditambahkan satu tetes indikator fenolftalin. Jika terbentuk warna merah muda, dilakukan penambahan $\mathrm{H}_{2} \mathrm{SO}_{4} 5 \mathrm{~N}$ tetes demi tetes sampai warna hilang. Kemudian ditambahkan $8 \mathrm{~mL}$ larutan campuran dan dihomogenkan. Larutan didiamkan selama 15 menit. Selanjutnya campuran tersebut dimasukkan ke dalam kuvet sebanyak $3 / 4$ bagian dari volume kuVet dan diukur absorbansinya dengan 
menggunakan spektrofotometer UV-Vis

pada panjang gelombang $880 \mathrm{~nm}$. Larutan campuran dibuat dengan mencampurkan

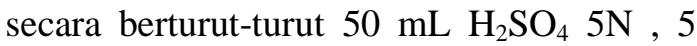
$\mathrm{mL}$ larutan kalium antimonil tartat, $15 \mathrm{~mL}$ larutan ammonium molibdat dan $30 \mathrm{~mL}$ larutan asam askorbat. Penentuan kadar fosfat ini dilakukan pada sampel limbah laundry sebelum dan sesudah proses pengolahan dengan karbon aktif.

\subsection{Penurunan Kadar surfaktan anionik}

\section{(deterjen)}

Penurunan kadar surfaktan nionik dilakukan dengan metode batch. Sampel air limbah sebanyak $100 \mathrm{~mL}$ dimasukkan kedalam gelas beaker. Kemudian ditambahkan karbon aktif sebagai adsorbent sebanyak 8 gram. Variasi karbon akif yang ditambahkan adalah dengan ukuran partikel yang lolos ayakan 60 mesh (-60), 120 mesh (-120) dan dan 200 mesh (-200). Air limbah deterjen dan karbon aktif diaduk menggunakan magnetic stirrer dengan kecepatan 400 rpm selama 75 menit. Hasil treatment disaring, kemudian filtratnya dianalisis dengan metode MBAS untuk menentukan kadar deterjennya.

\subsection{Penurunan kadar fosfat}

Penurunan kadar fosfat dalam limbah dilakukan dengan metode batch. Sampel air limbah sebanyak $50 \mathrm{~mL}$ dimasukkan kedalam gelas beaker. Kemudian ditambahkan karbon aktif sebagai adsorbent sebanyak 4 gram. Variasi karbon akif yang ditambahkan adalah dengan ukuran partikel yang lolos ayakan 60 mesh (-60), 120 mesh (-120) dan dan 200 mesh (-200). Air limbah deterjen dan karbon aktif diaduk menggunakan magnetic stirrer dengan kecepatan 400 rpm selama 75 menit. Hasil treatment disaring, kemudian filtratnya dianalisis sesuai dengan metode penentuan kadar fosfat.

\section{Hasil dan Pembahasan}

\subsection{Pembuatan kurva kalibrasi larutan MBAS}

Kurva kalibrasi dibuat sebagai dasar pengukuran konsentrasi deterjen dalam limbah laundry. Larutan standar MBAS dibuat dari larutan induk natrium lauril sulfat. Senyawa ini dipilih sebagai senyawa untuk larutan standar karena merupakan jenis surfaktan anionik yang banyak digunakan pada deterjen komersial. Kurva kalibrasi merupakan grafik yang menyatakan hubungan antara konsentrasi larutan standar dengan hasil pembacaan absorbansi larutan, yang hasilnya merupakan garis lurus. Tabel 1 memperlihatkan nilai absorbansi dari larutan standar MBAS pada $\begin{array}{llll}\text { panjang } & \text { gelombang } & 653 & \mathrm{~nm} \text {. }\end{array}$ 


\begin{tabular}{cc}
\multicolumn{2}{c}{ TABEL 1 ABSORBANSI LARUTAN STANDART MBAS } \\
\hline Konsentrasi standart (ppm) & Absorbansi \\
\hline 2 & 0,093 \\
\hline 4 & 0,240 \\
\hline 6 & 0,334 \\
\hline 8 & 0,494 \\
\hline 10 & 0,668 \\
\hline 12 & 0,856 \\
\hline
\end{tabular}

Dalam pembuatan kurva kalibrasi standar MBAS yang harus dilakukan adalah membuat beberapa larutan standar yang telah diketahui konsentrasinya dari analit yang akan ditentukan konsentrasinya dalam sampel. Fungsi dari larutan standar ini adalah sebagai standar dalam pengukur analit yang nantinya hasilnya akan diplotkan pada kurva standar untuk menentukan nilai regresi dari kurva. Dalam analisis ini digunakan konsentrasi larutan standar MBAS yang diperoleh melalui pengenceran larutan induk natrium lauril sulfat $1000 \mathrm{ppm}$ sehingga didapatkan larutan standar MBAS dengan konsentrasi 2, 4, 6, 8, 10 dan 12 ppm. Nilai absorbansi yang didapat kemudian diplotkan terhadap konsentrasi larutan standar sehingga diperoleh nilai koefisien korelasi (r). Jika nilai koefisien korelasi tersebut mendekati 1 atau >0,95 maka dapat dikatakan bahwa hasil dari pembuatan larutan standar memiliki tingkat keakuratan yang cukup baik. Dari plot kurva kalibrasi yang telah dilakukan didapatakan persmaan $\mathrm{y}=0,0709 \mathrm{x}-0,042$ dengan nilai koefisien korelasi (r) sebesar 0,9934. Hasil ini menunjukkan bahwa nilai absorbansi memiliki korelasi yang baik dengan konsentrasi larutan sehingga persamaan garis lurus yang diperolleh dapat digunakan untuk proses penentuan kadar deterjen dari sampel.

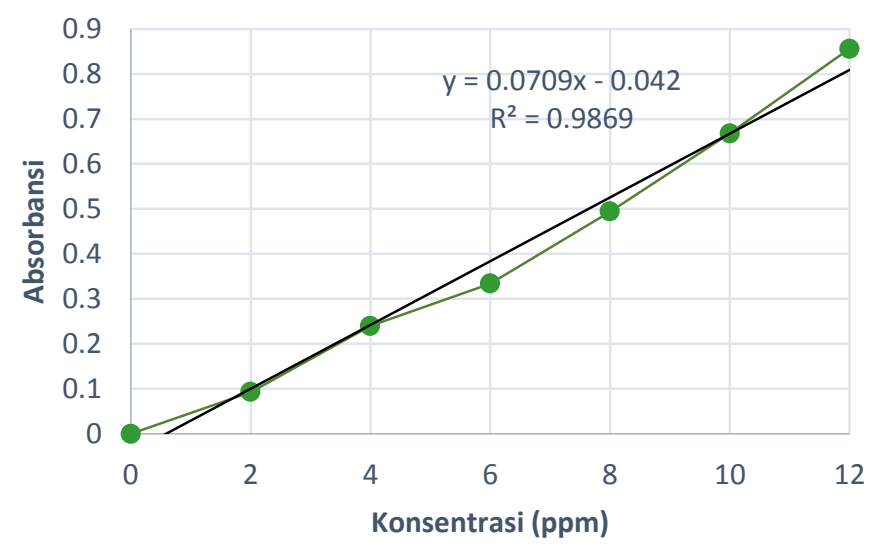

Gambar 1. Kurva Kalibrasi larutan standar MBAS 


\subsection{Penentuan kadar surfaktan anionik} atau deterjen dengan metode MBAS

Setelah penentuan kurva kalibrasi larutan standar, selanjutnya dilakukan ekstraksi surfaktan anionik dari limbah laundry. Tujuan dari perlakuan ini adalah agar surfaktan anionik terikat dengan metilen biru dan terlarut dalam fase kloroform. Jika kadar surfaktan anionik dalam sampel limbah tinggi, maka akan menunjukkan warna biru pekat pada fase kloroform. Dengan demikian, jumlah surfaktan anionik yang dianalisis selanjutnya dapat mewakili seluruh surfkatan anionik yang berada di limbah laundry.

Prinsip dari metode MBAS ini adalah surfaktan anionik akan berikatan dengan metilen biru membentuk senyawa kompleks berwarna biru yang larut dalam fase kloroform. Setelah diekstraksi, intensitas warna biru yang terbentuk diukur absorbansinya dengan spektrofotometer UV-Vis pada panjang gelombang $653 \mathrm{~nm}$ sesuai dengan panjang gelombang pada pembuatan kurva kalibrasi. Hasil pengukuran menunjukkan nilai absorbansi sebesar 0,7153 sehingga didapat nilai konsentrasi sebesar surfaktan anionik atau deterjen sebesar 10,65 ppm. Kadar surfaktan anionik atau deterjen pada sampel limbah laundry yang dianalisis melebihi baku mutu yang telah ditetapkan oleh Peraturan Daerah
Provinsi Jawa Timur Nomor 72 Tahun 2013, yakni dibawah 10 mg/L air limbah [11]. Berdasarkan hasil tersebut, dilakukan treatment untuk menurunkan kadar surfaktan anionik atau deterjent pada limbah laundry.

\subsection{Penurunan kadar surfaktan anionik} (detergen) dengan karbon aktif

Penurunan kadar surfaktan anionik (deterjen) dilakukan dengan menggunakan karbon aktif sebanyak 8 gram yang berfungsi sebagai adsorben. Penggunaan karbon aktif divariasi dengan ukuran mesh 60 atau $250 \mu \mathrm{m},-120$ atau $125 \mu \mathrm{m}$ dan -200 atau $75 \mu \mathrm{m}$. Tujuan penggunaan variasi adalah untuk mengetahui pengaruh ukuran partikel terhadap aktifitas penurunan kadar surfaktan anionik. Dilakukan pengadukan dengan kecepatan 400 rpm selama 75 menit agar karbon aktif dapat menyerap dengan lebih baik dan merata.

Larutan dengan campuran karbon aktif kemudian disaring dan diukur kadar surfaktannya dengan metode MBAS seperti pada pengukuran sampel limbah laundry awal sebelum perlakuan. Dari hasil pengukuran maka didapatkan absorbansi dari tiga variasi ukuran partikel sebagaimana ditampilkan pada Tabel 2. Hasil absorbansi kemudian dimasukan kedalam persamaan y $=0,0709 \mathrm{x}-0,042$ untuk mendapatkan konsentrasi dari masing-masing treatment. Data hasil perhitungan konsentrasi terdapat pada

Tabel

3. 
TABEL 2. ABSORBANSI KADAR SURFAKTAN DENGAN KARBON AKTIF

\begin{tabular}{cccc}
\hline $\begin{array}{c}\text { Variasi } \\
\text { karbon aktif }\end{array}$ & Absorbansi 1 & Absorbansi 2 & $\begin{array}{c}\text { Absorbansi } \\
\text { Rata-rata }\end{array}$ \\
\hline Mesh 60 & 0,409 & 0,410 & 0,409 \\
\hline Mesh 120 & 0,278 & 0,278 & 0,278 \\
\hline Mesh 200 & 0,178 & 0,178 & 0,278 \\
\hline
\end{tabular}

TABEL 3 KONSENTRASI SAMPEL SETELAH TREATMENT

\begin{tabular}{ccc}
\hline Variasi Karbon Aktif & $\begin{array}{c}\text { Konsentrasi } \\
\text { (ppm) }\end{array}$ & $\begin{array}{c}\text { Kapasitas adsorpsi } \\
\text { (mg/g) }\end{array}$ \\
\hline Mesh -60 & 6,3681 & 0.054 \\
\hline Mesh -120 & 4,5133 & 0.077 \\
\hline Mesh -200 & 3,1029 & 0.094 \\
\hline
\end{tabular}

Hasil penentuan konsentrasi pada Tabel 3 menunjukkan bahwa karbon aktif dapat digunakan sebagai adsorben yang baik untuk menurunkan kadar surfaktan atau deterjen pada limbah laundry. Hal ini dibuktikan dari penurunan konsentrasi yang sangat signifikan pada sebelum dan sesudah treatment. Hasil treatment menunjukkan bahwa seluruh sampel menunjukkan konsentrasi yang berada di bawah ambang batas maksimal kandungan surfaktan anionik di limbah sebesar $10 \mathrm{mg} / \mathrm{L}$. Namun demikian, aplikasi skala besar penggunaan karbon aktif dalam limbah in lebih kompleks karena karbon aktif memiliki kapasitas adsorpsi tertentu. Artinya, kemampuan karon aktif untuk mengadsorpsi surfaktan anionik terbatas pada nilai tertentu. Perhitungan kapasitas adorpsi karbon aktif dari berbagai ukuran partikel yang ditunjukkan pada Tabel 3 menunjukkan bahwa semaikn kecil ukuran partikel karbon aktif, semakin tinggi pula kapasitas adsorpsinya. Hal ini dapat disebabkan karena ukuran partikel yang semakin kecil memiliki luas permukaan yang semakin besar sehingga lebih banyak situs atau permukaan karbon aktif yang dapat digunakan sebagai tempat teradsorpsinya surfaktan kationik.

\subsection{Kinetika adsorbs surfaktan pada karbon aktif}

Proses penyerapan atau adsorpsi oleh suatu adsorben dipengaruhi banyak faktor dan juga memiliki pola isotermal adsorpsi tertentu yang spesifik. Faktor-faktor yang mempengaruhi dalam proses adsorpsi antara lain yaitu jenis adsorben, jenis zat yang diserap, luas permukaan adsorben, konsentrasi zat yang diadsorpsi dan suhu. Oleh karena faktor-faktor tersebut maka setiap adsorben yang menyerap suatu zat satu dengan zat lain tidak akan mempunyai pola isoterm adsorpsi yang sama. Diketahui bahwa terdapat dua jenis persamaan pola isoterm adsorpsi yang sering digunakan pada proses adsorpsi dalam larutan yaitu 
persamaan adsorpsi Langmuir dan

Freundlich.

Pengujian pola isoterm adsorpsi yang sesuai untuk proses penyerapan surfaktan anionik oleh karbon aktif dilakukan dengan

$\mathrm{Ce} /(\mathrm{x} / \mathrm{m})=1 / \mathrm{ab}+1 / \mathrm{aCe}$

$\log (x / m)=\log k+1 / n \log C e$

dimana:

$\mathrm{Ce}=$ konsentrasi surfaktan anionik dalam larutan setelah diadsorpsi

$x / m=$ massa surfaktan anionik yang diserap per gram karbon aktif

$b=$ parameter afinitas atau konstanta Langmuir

$a$ dan $k=$ kapasitas $/$ daya adsorpsi maksimum (mg/gram)

Penentuan persamaan isotermal Langmuir dan Fruendlich dilakukan dengan menghitung harga $x / m, \quad \mathrm{Ce} /(x / m), \quad \log$ $\mathrm{Ce} /(\mathrm{x} / \mathrm{m})$ dan $\log \mathrm{Ce}$ seperti yang terlihat pada Tabel 4. Data adsorpsi diperoleh dari penyerapan surfaktan anionik oleh karbon aktif dengan variasi ukuran mesh. Data pada Tabel 4 selanjutnya diplotkan berdasarkan persamaan Langmuir dan Freundlich dimana perhitungan menggunakan persamaan Langmuir dan Freundlich. Uji persamaan Langmuir dilakukan dengan menggunakan Persamaan 1 sementara uji persamaan Freundlich dilakukan dengan Persamaan 2 [12].

Tabel 4. Perhitungan harga $x / M, C e /(x / M)$, log X/M, DAN log Ce

\begin{tabular}{cccccccc}
\hline $\begin{array}{c}\text { Ukuran } \\
\text { mesh }\end{array}$ & $\begin{array}{c}\text { ppm } \\
\text { awal }\end{array}$ & $\begin{array}{c}\text { ppm } \\
\text { teradsorbsi }\end{array}$ & $\begin{array}{c}\text { Ce } \\
\text { (ppm } \\
\text { sisa) }\end{array}$ & $\begin{array}{c}\mathrm{x} / \mathrm{m} \\
(\mathrm{ppm} / \mathrm{g})\end{array}$ & $\begin{array}{c}\mathrm{Ce} / \mathrm{x} / \mathrm{m}) \\
(\mathrm{x} / \mathrm{m})\end{array}$ & log Ce \\
\hline-60 & 10.655 & 4.287 & 6.368 & 0.535 & 11.881 & -0.270 & 1.074 \\
\hline-120 & 10.655 & 6.142 & 4.513 & 0.767 & 5.878 & -0.114 & 0.769 \\
\hline-200 & 10.655 & 7.552 & 3.102 & 0.944 & 3.286 & -0.024 & 0.516 \\
\hline
\end{tabular}




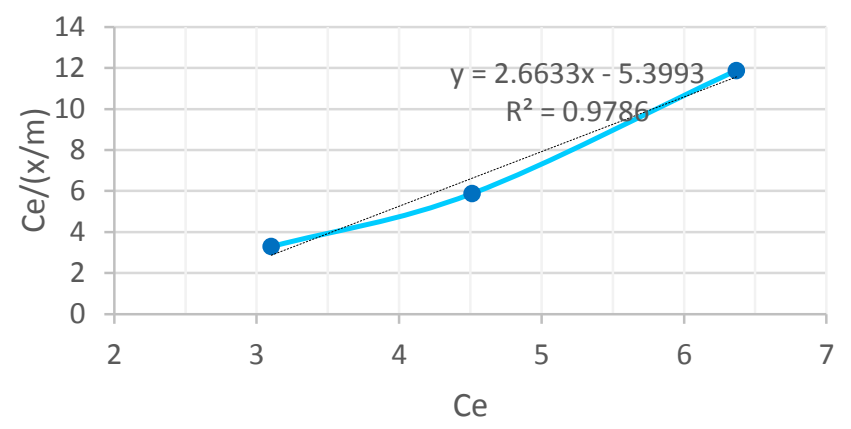

Gambar 2 PersamaAn AdSORPSI ISOTERMAL LANGMUIR DARI CE/(x/M) Versus Ce

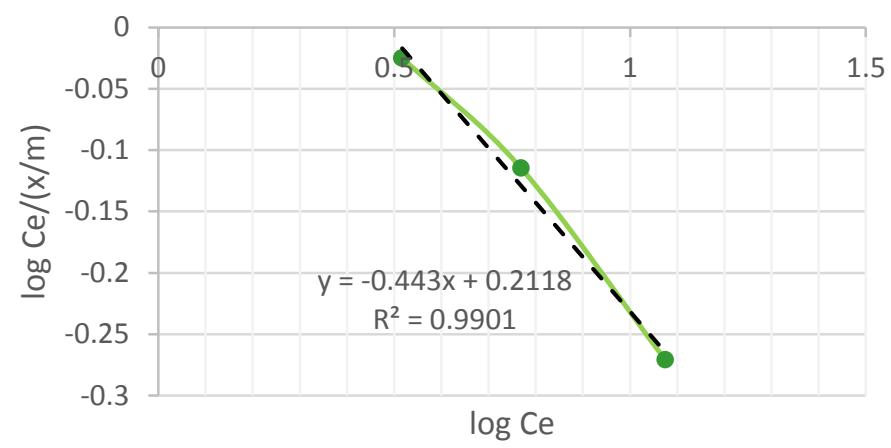

Gambar 3 PeRSAMAAN AdSORPSI ISOTERMAL FREUndLICH DARI LOGCE/(x/M) VERSUS LOGCE

Pengujian persamaan adsorpsi Langmuir dan persamaan adsorpsi Freundlich dibuktikan dengan grafik linierisasi yang baik dan mempunyai harga koefisien determinasi $\mathrm{r}^{2} \geq 0.9$ (mendekati angka 1). Dari Gambar 3 dan 4 terlihat bahwa persamaan adsorpsi surfaktan anionik oleh karbon aktif lebih memenuhi persamaan adsorpsi Freundlich dengan nilai $r^{2}$ sebesar 0,9901 ( $R=0,995)$. Hasil ini menunjukkan bahwa proses adsorpsi yang terjadi antara karbon aktif dengan surfaktan anionik lebih bersifat fisik, dimana ikatan yang terbentuk merupakan ikatan fisika dengan terdapat terdapat lebih dari satu lapisan permukaan (multilayer). Namun demikian, karena adsorpsi tersebut juga memenuhi persamaan
Langmuir, maka terdapat kemungkinan pengaruh ikatan kimia dalam proses adsorpsi karbon aktif dengan surfaktan anionik. Selain itu, walaupun mampu mebentuk lapisan multilayer di permukaan karbon aktif, kapasitas adsorpsi surfaktan anionik juga tetap dipengaruhi oleh luas permukaan karbon aktif.

\subsection{Penentuan kadar fosfat pada limbah laundry}

Penentuan kadar fosfat limbah laundry diawali dengan pembuatan kurva kalibrasi fosfat. Larutan fosfat yang digunakan sebagai standar adalah larutan yang dibuat dari $\mathrm{KH}_{2} \mathrm{PO}_{4}$. Konsentrasi larutan fosfat divariasikan sebesar 2, 4, 6, 8, 10, dan 12 ppm. Pada tiap konsentrasi 
larutan tersebut, ditambahkan 1 tetes indikator phenolphthalein (pp) sebagai indikator perubahan warna. Selanjutnya apabila terjadi perubahan warna larutan menjadi pink yang menandakan bahwa larutan bersifat basa diteteskan $\mathrm{H}_{2} \mathrm{SO}_{4} 5 \mathrm{~N}$ yang bersifat asam kuat untuk merubah larutan pada kondisi netral dengan ditandai perubahan menjadi tidak berwarna. Kemudian, dilakukan penambahan $\quad 8 \quad \mathrm{~mL}$ larutan campuran sebagaimana pada analisis deterjen dan dihomogenkan sampai terbentuk larutan berwarna biru. Larutan standar tersebut dilakukan pengukuran dengan Spektrofotometer UV-Vis pada panjang gelombang $880 \mathrm{~nm}$. Hasil absorbansi larutan standar fosfat ditampilkan pada Tabel 5. Data konsentrasi dan absorbansi pada Tabel 5 selanjutnya di plotkan sehingga diperoleh kurva kalibrasi fosfat sebagaimana ditampilkan pada Gambar 4. Dari hasil plot kurva standar didapatkan persamaan $\mathrm{y}=0,1026 \mathrm{x}+$ 0,0779 dengan $r^{2}$ sebesar 0,9836 ( $\left.\mathrm{r}=0,9917\right)$. Karena $r>0,95$ maka dapat dikatakan bahwa kurva standar telah memenuhi persyaratan sehingga dapat digunakan sebagai acuan penentuan konsentrasi kadar fosfat dari sampel limbah deterjen yang akan dianalisa.

TABEL 5 ABSORBANSI LARUTAN STANDAR FOSFAT

\begin{tabular}{cccc}
\hline $\begin{array}{c}\text { Konsentrasi } \\
\text { (ppm) }\end{array}$ & \multicolumn{2}{c}{ Absorbansi } & $\begin{array}{c}\text { Absorbansi } \\
\text { Rata-rata }\end{array}$ \\
\hline 2 & 0,274 & 0,273 & 0,2735 \\
\hline 4 & 0,563 & 0,562 & 0,5625 \\
\hline 6 & 0,756 & 0,754 & 0,755 \\
\hline 8 & 0,921 & 0,921 & 0,921 \\
\hline 10 & 1,09 & 1,093 & 1,0915 \\
\hline 12 & 1,249 & 1,251 & 1,250 \\
\hline
\end{tabular}

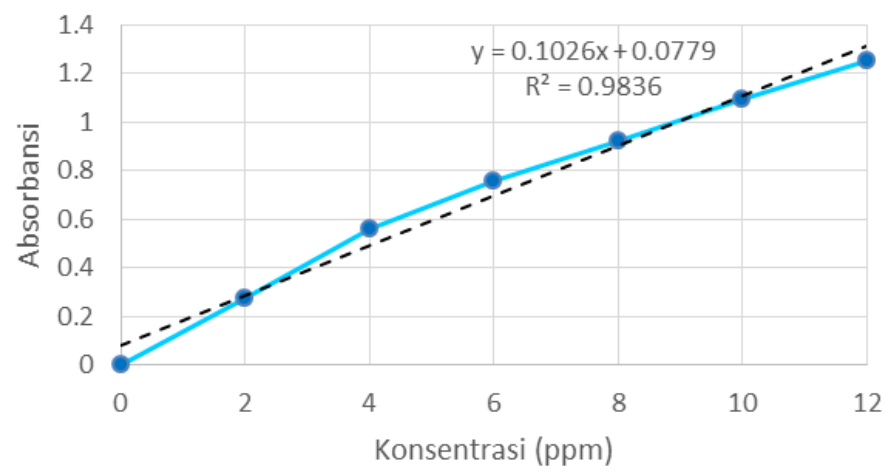

Gambar 4. Kurva Kalibrasi fosfat

Pada pengukuran kadar fosfat dalam sampel, $50 \mathrm{~mL}$ limbah deterjen ditetesi dengan indikator pp, pada penetesan terjadi perubahan warna menjadi merah muda yang mengindikasikan bahwa sampel bersifat basa. Selanjutnya, ditambahkan 1 tetes $\mathrm{H}_{2} \mathrm{SO}_{4} 5 \mathrm{~N}$ untuk merubah larutan menjadi kondisi netral yang diindikasikan dengan perubahan warna menjadi tidak berwarna. Pada saat ditambahkan $8 \mathrm{~mL}$ larutan 
campuran terjadi perubahan warna menjadi biru pekat. Sampel kemudian diukur absorbansinya dengan spektrofotometer UVvis pada panjang gelombang $880 \mathrm{~nm}$. Hasil pengukuran menunjukkan nilai absorbansi sebesar 1,5295. Nilai absorbansi tersebut melebihi nilai absorbansi yang baik untuk analisis menggunakan spektrofotometer UVvis dan berada diluar rentang interpolasi kurva kalibrasi yang diperoleh. Namun demikian, nilai tersebut mengindikasikan bahwa konsentrasi fosfat dalam cairan limbah sangat tinggi. Oleh karena itu, sampel kemudian diencerkan untuk mendapatkan absorbansi yang berada di antara rentang interpolasi kurva kalibrasi. Proses pengenceran menghasilkan absorbansi sebesar 0,8036 dengan faktor pengenceran 2. Nilai tersebut sudah berada pada rentang interpolasi kurva kalibrasi fosfat. Penghitungan konsentrasi berdasarkan persamaan regresi dengan melibatkan faktor pengenceran menghasilkan konsentrasi fosfat dalam sampel sebesar 14,148 ppm. Hal ini menandakan bahwa sampel limbah deterjen memiliki kadar fosfat yang tinggi dan telah melewati batas baku mutu Pergub Jatim yaitu sebesar 10 ppm [10].

\subsection{Penurunan kadar fosfat dengan karbon aktif}

Fosfat dapat memicu pertumbuhan alga pada air, apabila terjadi pertumbuhan yang berlebihan maka akan menyebabkan sulitnya sinar matahari untuk masuk ke dalam air dan terganggunya proses fotosintesis. Selain itu, alga menyebabkan kurangnya oksigen bagi makhluk hidup dalam air dikarenakan oksigen yang digunakan oleh alga itu sendiri. Bukan hanya itu, pertumbuhan alga dalam jumlah banyak dapat memicu tersumbatnya saluran air pada sungai sehingga menyebabkan aliran sungai menjadi tidak lancar [7][10].

Hasil penelitian pada penentuan kadar fosfat menunjukkan bahwa konsentrasi pada sampel melebihi batas baku mutu sehingga, perlu dilakukannya treatment untuk mengurangi kadar fosfat. Treatment dilakukan pada sampel yang telah diperlakukan awal seperti pada pembuatan kurva kalibrasi, namun di-treatment dengan menggunakan karbon aktif sebesar 4 gram yang berfungsi sebagai adsorbent. Penurunan kadar fosfat dilakukan dengan variasi ukuran karbon aktif -60, -120 dan 200 mesh. Tujuan penggunaan variasi adalah untuk mengetahui pengaruh ukuran partikel terhadap aktivitas penurunan kadar fosfat. Penurunan dilakukan dengan sistem batch disertai pengadukan dengan kecepatan 400 rpm selama 75 menit agar karbon aktif dapat menyerap dengan lebih baik dan merata. Larutan dengan campuran karbon aktif kemudian disaring dan diukur filtrat dengan spektrofotometer UV-vis pada panjang gelombang $880 \mathrm{~nm}$ dengan dua kali pengukuran. Dari hasil pengukuran maka didapatkan serapan dari tiga variasi seperti ditunjukkan pada Tabel pada Tabel 6 . 
W.P. Utomo, dkk. Akta Kimia Indonesia 3(1), 2018, 127-140

TABEL 6 ABSORBANSI KADAR FOSFAT DENGAN KARBON AKTIF

\begin{tabular}{ccccc}
\hline $\begin{array}{c}\text { Variasi karbon } \\
\text { aktif }\end{array}$ & $\begin{array}{c}\text { Absorbansi } \\
\mathbf{1}\end{array}$ & Absorbansi 2 & $\begin{array}{c}\text { Absorbansi } \\
\text { Rata-rata }\end{array}$ & Konsentrasi (ppm) \\
\hline Mesh 60 & 0,024 & 0,025 & 0,0245 & 0,000 \\
\hline Mesh 120 & 0,014 & 0,014 & 0,014 & 0,000 \\
\hline Mesh 200 & 0,009 & 0,009 & 0,009 & 0,000 \\
\hline
\end{tabular}

Hasil perhitungan konsentrasi menunjukkan bahwa konsentrasi fosfat dalam limbah deterjen sangat rendah dan berada dibawah batas deteksi. Hal ini menunjukkan bahwa kemampuan adsorpsi karbon aktif dalam mengadsorpi fosfat dari limbah laundry sangat tinggi. Analisis pada nilai absorbansi menunjukkan bahwa semakin kecil ukuran partikel karbon aktif, semakin besar pula kapasitas karbon aktif dalam mengadsorpsi fosfat. Hasil ini menunjukkan bahwa karbon aktif sangat berpotensi digunakan sebagai material adsorben untuk mengadsorpsi fosfat dari limbah laundry.

\section{Kesimpulan}

Kadar surfaktan anionik (deterjen) dan fosfat dalam air limbah laundry di Keputih, Sukolilo, Surabaya melebihi ambang batas yang telah ditentukan oleh Pergub Jatim yakni sebesar 10,65 ppm untuk kadar surfaktan anionik (deterjen) dan 14,148 ppm untuk kadar fosfat. Penurunan kadar deterjen dan fosfat tersebut berhasil dilakukan dengan menggunkaan karbon aktif. Hasil yang diperoleh menunjukkan bahwa semakin kecil ukuran partikel, semakin tinggi kapasitas adsorpsinya. Hasil adsorpsi surfaktan anionik terbaik didapatkan dengan variasi ukuran -200 mesh dengan kandungan srufaktan anionik menjadi 3,102 ppm. Hasil penurunan kadar fosfat dengan karbon aktif menunjukkan bahwa kandungan fosfat setelah proses tretament berkurang signifikan dibawah batas deteksi.

\section{Daftar Pustaka}

[1] Suripin. 2002. Pelestarian Sumberdaya Tanah dan Air. Penerbit ANDI. Yogyakarta.

[2] Sofia, Y., Tontowi, dan S. Rahayu. 2010. "Penelitian Pengolahan Air Sungai Yang Tercemar Oleh Bahan Organik". Jurnal Sumber Daya Air, 6. 145-160.

[3] Simon, S.B. dan R. Hidayat. 2008. "Pengendalian Pencemaran Sumber Air Dengan Ekoteknologi (Wetland Buatan)". Jurnal Sumber Daya Air, 4. 111-124.

[4] Suriawiria, U. 1996. Air dalam Kehidupan dan Lingkungan yang Sehat. Penerbit Alumni. Bandung.

[5] Santi, S. S. (2009). Penurunan Konsentrasi Surfaktan Pada Limbah Deterjen Dengan Proses Photokatalitik Sinar UV. Jurnal Teknik Kimia Vol 4 No 1, 260-264.

[6] Rosariawari, F. (2008). Penurunan Konsentrasi Limbah Deterjen Menggunakan Furnace Bottom Ash (FBA). Jurnal Rekayasa Perencanaan, 4 (3).

[7] Majid, M., Rahmi, A., Umar, R dan Hengky, H.K., 2017, "Efektivitas Penggunaan Karbon Aktif ada Penurunan Kadar Fosfat Limbah Cair Usaha Laundry di Kota Pare-Pare Sulawesi Selatan", Prosiding Seminar Nasional IKAKESMADA "Peran Tenaga Kesehatan dalam Pelaksanaan SDGs" 
[8] Rahimah, Z., Heldawati, H. dan Syauqiah, I., (2016), “ Pengolahan Limbah Deterjen dengan Metode Koagulasi-Flokulasi Menggunakan Koagulan Kapur dan PAC", Konversi, 5 (2), 13-19

[9] Arneli, (2010), "Sublasi Surfaktan dari Larutan Deterjgen dan Larutan Detergen Sisa Cucian serta Penggunaannya Kembali sebagai Detergen, Jurnal Kimia Sains dan Aplikasi, 13 (1), 4-7

[10] Ndani, L.P.L.M., (2016), "Penentuan Kadar Senyawa Fosfat di Sungai Way Kuripan dan Way Kuala dengan Spektrofotometri UV-Vis", Skripsi, Jurusan kimia FMIPA, Universitas Lampung.

[11] Peraturan Gubernur Jawa Timur Nomor 72 Tahun 2013 tentang Baku Mutu Air Limbah Bagi Industri dan/atau Kegiatan Usaha Lainnya

[12] Handayani, M. \& S, E., 2009. Uji Persamaan Langmuir dan freundlich Pada Penyerapan Limbah Crom (VI) oleh Zeolit. Bandung, Pusat Penelitian Metalurgi-LIPI. 